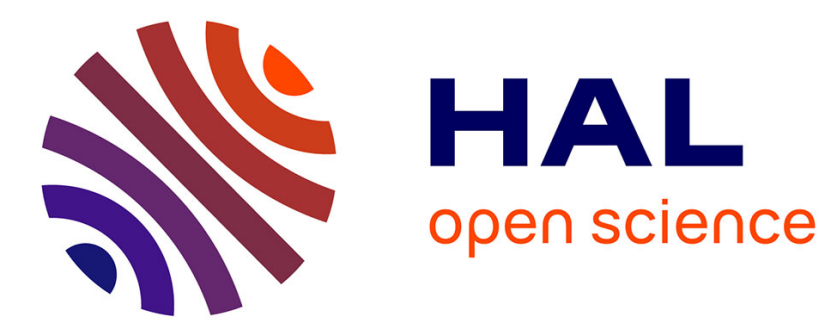

\title{
Mapping crustal stress and strain in southwest British Columbia
}

\author{
N.J. Balfour, J.F. Cassidy, S.E. Dosso, Stephane Mazzotti
}

\section{To cite this version:}

N.J. Balfour, J.F. Cassidy, S.E. Dosso, Stephane Mazzotti. Mapping crustal stress and strain in southwest British Columbia. Journal of Geophysical Research, 2011, 116, pp.B03314. 10.1029/2010JB008003 . hal-00853734

\section{HAL Id: hal-00853734 https://hal.science/hal-00853734}

Submitted on 30 Apr 2021

HAL is a multi-disciplinary open access archive for the deposit and dissemination of scientific research documents, whether they are published or not. The documents may come from teaching and research institutions in France or abroad, or from public or private research centers.
L'archive ouverte pluridisciplinaire HAL, est destinée au dépôt et à la diffusion de documents scientifiques de niveau recherche, publiés ou non, émanant des établissements d'enseignement et de recherche français ou étrangers, des laboratoires publics ou privés. 


\title{
Mapping crustal stress and strain in southwest British Columbia
}

\author{
N. J. Balfour, ${ }^{1,2}$ J. F. Cassidy, ${ }^{1,2}$ S. E. Dosso, ${ }^{1}$ and S. Mazzotti ${ }^{1,2}$ \\ Received 17 September 2010; revised 6 December 2010; accepted 29 December 2010; published 31 March 2011.
}

[1] This paper investigates the orientation and sources of stress in the forearc of the Cascadia subduction zone in southwest British Columbia, using Bayesian inversion results from focal mechanism data and comparing results with GPS derived short-term strain rates. The subduction margin in this region includes a change in orientation from N-S in Washington State to NW-SE in British Columbia. Over 1000 focal mechanisms from North American crustal earthquakes have been calculated to identify the dominant style of faulting, and $\sim 600$ were inverted to estimate the principal stress orientations and the stress ratio. Our results indicate the maximum horizontal compressive stress orientation changes with distance to the trench, from approximately margin-normal along the coast to approximately margin-parallel $100-150 \mathrm{~km}$ inland from the coast. Comparing stress orientations with GPS data, we relate the margin-normal stress direction to subductionrelated strain rates due to the locked interface between the North American and Juan de Fuca plates just west of Vancouver Island. Further from the margin the plates are coupled less strongly, and the margin-parallel maximum horizontal compressive stress in the North American Plate relates to the northward push of the Oregon Block, which is also observed in the horizontal shortening direction of the residual strain rates, after the subduction component is removed.

Citation: Balfour, N. J., J. F. Cassidy, S. E. Dosso, and S. Mazzotti (2011), Mapping crustal stress and strain in southwest British Columbia, J. Geophys. Res., 116, B03314, doi:10.1029/2010JB008003.

\section{Introduction}

[2] Southwest British Columbia is located above the Cascadia subduction zone, where the young Juan de Fuca plate subducts beneath the North American Plate at a rate of $\sim 40 \mathrm{~mm} / \mathrm{yr}$ [DeMets et al., 1990, 1994] as shown in Figure 1. Crustal seismicity is concentrated in the Puget Sound and southern Vancouver Island regions. In many areas, hypocenter depths span the entire crustal thickness $(\sim 30 \mathrm{~km}$ beneath Vancouver); however, they shallow to the east of Vancouver in the Coast Mountains to $<15 \mathrm{~km}$ and along the west coast of Vancouver Island (Figure 1). The largest known crustal earthquake in the region $\left(\mathrm{M}_{s} 7.3\right)$ occurred in 1946 on Vancouver Island (Figure 1).

[3] The majority of research on the Cascadia subduction zone has focused on subduction earthquakes that rupture the interface between the plates and could cause widespread damage along the coast of British Columbia, Washington, Oregon and northern California [Hyndman et al., 1996]. However, fewer studies have been carried out to understand faulting in the North American crust in British Columbia that can produce large, crustal earthquakes up to M 7.5. Southwest British Columbia represents a unique region of

\footnotetext{
${ }^{1}$ School of Earth and Ocean Sciences, University of Victoria, Victoria, British Columbia, Canada.

${ }^{2}$ Pacific Geoscience Centre, Geological Survey of Canada, Sidney, British Columbia, Canada.

Copyright 2011 by the American Geophysical Union. 0148-0227/11/2010JB008003
}

the Cascadia subduction zone due to the change in the strike of the margin. In addition, there are variations in the style of faulting in the crust and complex seismicity patterns that do not appear to align with surface faulting features. To understand the faulting in the region, and the seismic hazard posed on the surrounding populations, it is necessary to better understand the forces driving faulting.

[4] To date, relatively few focal mechanisms have been determined for earthquakes in British Columbia. Focal mechanisms have been calculated for specific significant earthquakes (main shock and aftershocks) [Cassidy et al., 2000; Rogers and Hasegawa, 1978] or regions of interest such as within the subducting Juan de Fuca plate [Wada et al., 2010; Bolton, 2003]. Only a few studies have looked at focal mechanisms over decadal time scales and have included small crustal earthquakes $(\mathrm{M}<3)$. Mulder [1995] determined focal mechanisms for 111 crustal earthquakes as small as magnitude 1.0 from 1975-1991 (Figure 2, blue). Ristau et al. [2007] set up an automated method for determining regional moment tensor solutions for moderate sized earthquakes $(M \geq 4)$ and the Pacific Geoscience Centre has a catalogue of these back to 1995 (Figure 2, red). Focal mechanisms for smaller events from 1992-2001 have been determined by various analysts but have not been reviewed and graded for quality.

[5] Formal stress inversions have proved difficult with seemingly unstable results due to the sparse focal mechanism data set. Mulder [1995] investigated stress in the region by considering composite $\mathrm{P}$ and $\mathrm{T}$ axes' plots and inverting focal mechanisms for stress using the Focal 


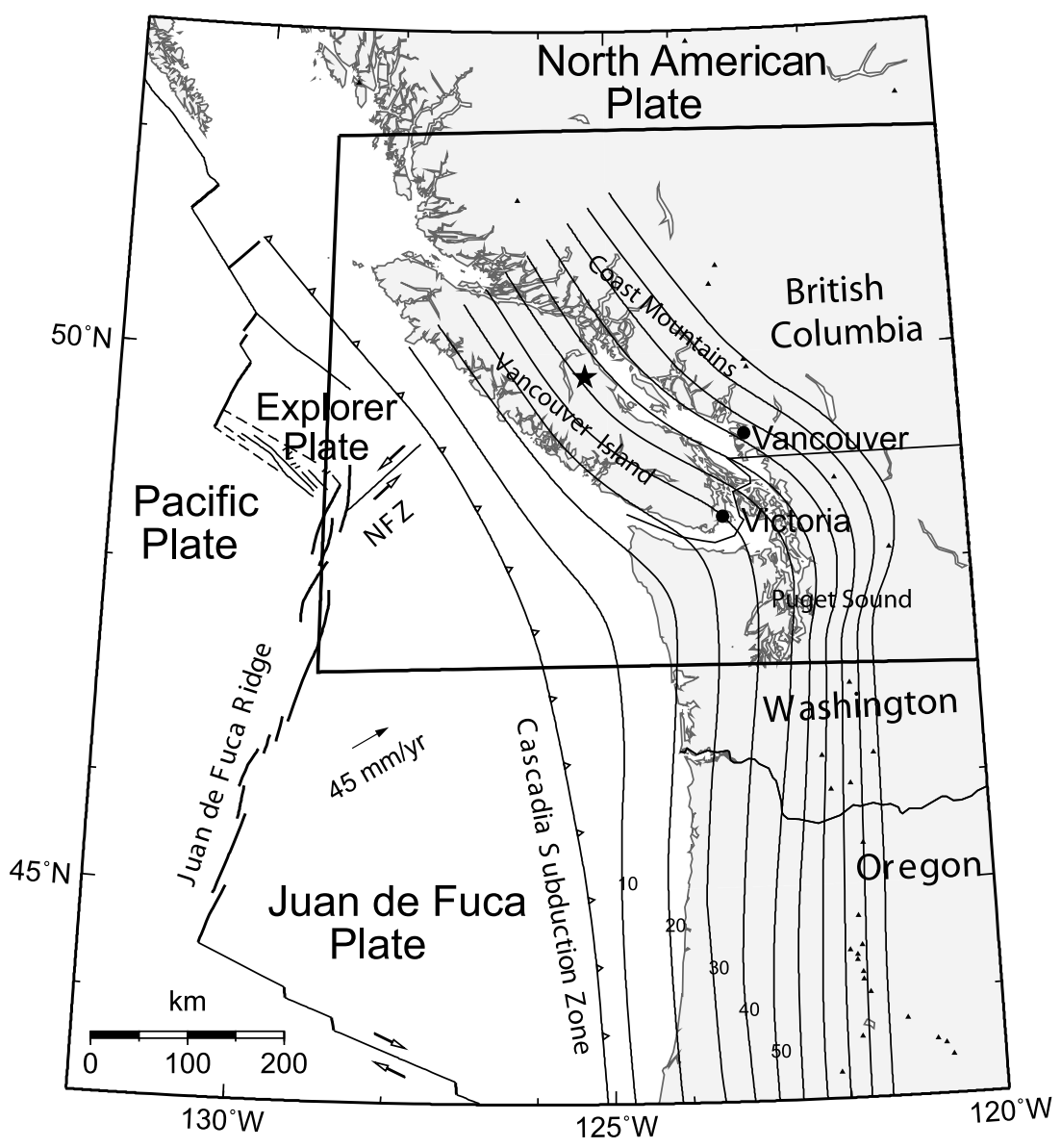

Figure 1. Northern Cascadia subduction zone. Contours show depth to the top of the subducting slab in kilometers [McCrory, 2004]. Area outlined by a box is the region considered in this study. The star shows the approximate location of the M 7.31946 Vancouver Island earthquake.

Mechanism Stress Inversion package by Gephart and Forsyth [1984] and Gephart [1990]. The inversion provided good first-order estimates of the trend/plunge of the principle stress orientations (maximum $\mathrm{S}_{1}=10 / 173^{\circ}$, intermediate $S_{2}=06 / 082^{\circ}$ and minimum $S_{3}=78 / 322^{\circ}$ ); however, the approach assumes the stress is homogeneous over the entire region. This assumption is a crude approximation due to plate coupling along the subduction interface and changes in margin strike through this region. Mulder [1995] mentions variations in the orientation of the $\mathrm{P}$ and $\mathrm{T}$ axes with distance from the margin that alludes to this; however, no formal inversions were performed on subsets of the data because of the lack of focal mechanisms along the west coast of Vancouver Island (Figure 2). Ristau et al. [2007] used moment tensor solutions to invert for stress but obtained unstable results for Vancouver Island, probably due to the smaller number of crustal events with $\mathrm{M}>4$ and variation in the stress field over the region which was assumed homogeneous in the inversion.

[6] These studies led to the computation of numerical models to explain the origin of margin-parallel stresses in the forearc of the Cascadia subduction zone. Stresses in the forearc are explained by Wang [1996], Wang and Jiangheng [1999] and Wang [2000] as being related to the balance between the subduction coupling force (strength of the

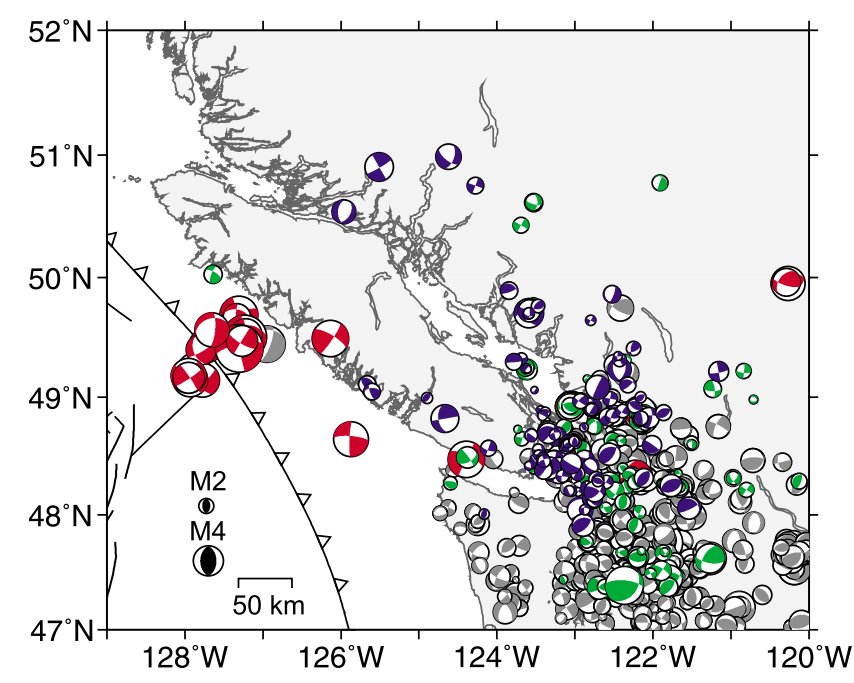

Figure 2. Source mechanisms of crustal earthquakes in the study area from previous studies: moment tensor solutions from Ristau et al. [2007] are in red, focal mechanisms from 1975-1991 from Mulder [1995] are in blue, other CNSN focal mechanisms from 1992-2002 are in green, and PNSN focal mechanisms are in grey. Source mechanisms are scaled according to magnitude. 


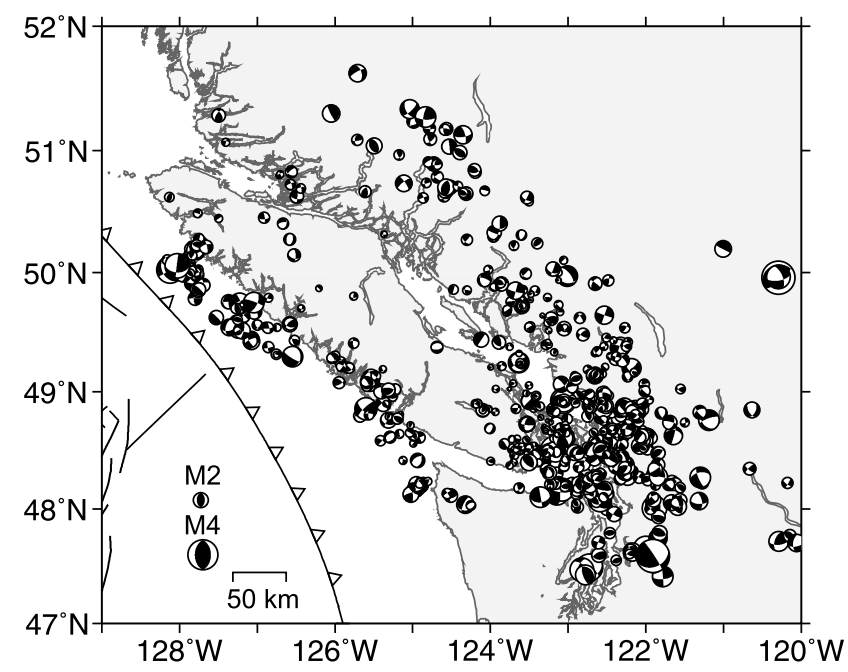

Figure 3. Focal mechanisms of crustal earthquakes determined in this study using FPFIT (black).

subduction fault) and the gravitational force from the continental margin topography. Wang and Jiangheng [1999] suggest that Cascadia has a low-stress forearc because the margin-normal compression from subduction does not seem to exceed the vertical stress from topography due to weak coupling along the subduction fault.

[7] Studies of crustal seismicity in the Cascadia forearc have tried to determine the validity of these models by investigating stress and strain. Currie et al. [2001] related the fast direction of crustal anisotropy to margin-parallel compression stress by comparing their shear wave splitting results to the maximum compressive stress direction determined from earthquake focal mechanisms and borehole stress studies across Cascadia. Lewis et al. [2003] investigated variations in strain from both earthquake focal mechanism inversions and geodetic observations along the Cascadia forearc from southern Oregon to northern Washington. They suggest that strain determined from focal mechanisms reflected the nonrecoverable component of deformation related to the rotation of the Oregon coast block defined by McCaffrey et al. [2000].

[8] In this study we create a new Canadian National Seismic Network (CNSN) focal mechanism database by (1) computing focal mechanisms from first motion observations of 550 small events (M 1-4) in the North American crust from 2002-2009; (2) reviewing mechanisms determined from 1992-2001 for consistent quality control to incorporate them with appropriate uncertainties into the database; and (3) combining previously determined focal mechanisms from 1975-1991 by Mulder [1995] with the new solutions from (1) and (2) to complete the database. With the completed database, we perform stress inversions on spatial subsets of the data to investigate variation in stress direction and examine whether stress within the region is homogeneous.

\section{Focal Mechanism Determination}

[9] The source mechanism of an earthquake is commonly described by a focal mechanism or moment tensor. Focal mechanisms are determined using the polarity of the direct $\mathrm{P}$ wave and/or the SV/P amplitude ratio and the takeoff angle of the ray from the source. Moment tensor solutions require more complex computation involving waveform inversion techniques.

[10] The data coverage of the focal sphere is dependent on the station geometry, and poor coverage can result in poorly defined focal mechanisms with multiple solutions that fit the observations. Uncertainties in estimated focal mechanism parameters are often poorly defined, but are frequently described in terms of the range of solutions that fit all $\mathrm{P}$ wave observations. It is often difficult to differentiate between the fault plane and the auxiliary plane unless independent information is available, such as a surface break of a fault. Polarity reversals are another common problem and were corrected for at two CNSN stations in British Columbia.

[11] In this study, the FPFIT method from Reasenberg and Oppenheimer [1985] is used to compute focal mechanisms. This inversion uses a two-stage grid search for the solution that minimizes the misfit with observed $\mathrm{P}$ wave first motions. The grid searches involve an initial coarse grid over the entire range of solution parameters $\left(10^{\circ}\right.$ increments $)$ followed by a smaller grid ( $1^{\circ}$ increments) to refine the solution. The method includes two weighting functions. An observational weighting is based on one or more of the $\mathrm{P}$ wave pick uncertainty, signal-to-noise ratio, or event-tostation distance. We choose to use the event-to-station

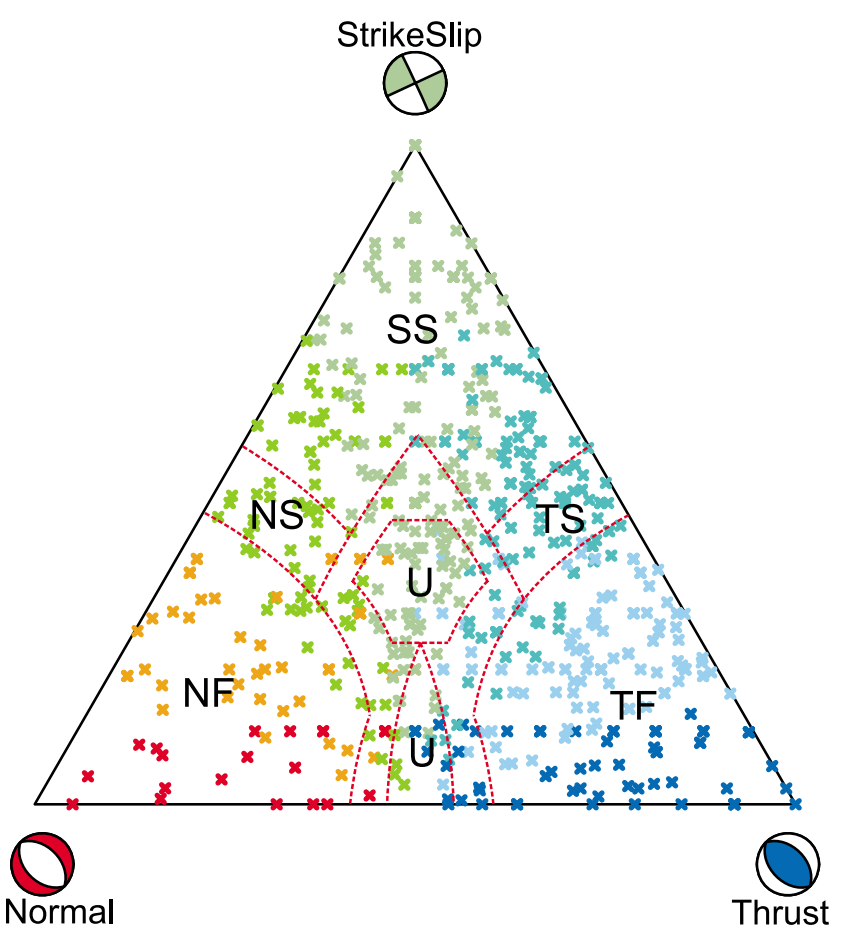

Figure 4. Ternary plot of focal mechanism data. Each point is plotted based on the plunge of the $\mathrm{P}, \mathrm{T}$, and $\mathrm{B}$ axes of the mechanism [Frohlich, 1992]. The colors represent the rake of the focal mechanism: red is pure normal, blue is pure thrust, and green is pure strike-slip. The dashed lines divide the triangle into faulting styles based on definitions by Zoback [1992]: NF is normal faulting, NS is normal and strike-slip, SS is strike-slip, TS is thrust and strike-slip, TF is thrust faulting, and $U$ is undefined. 


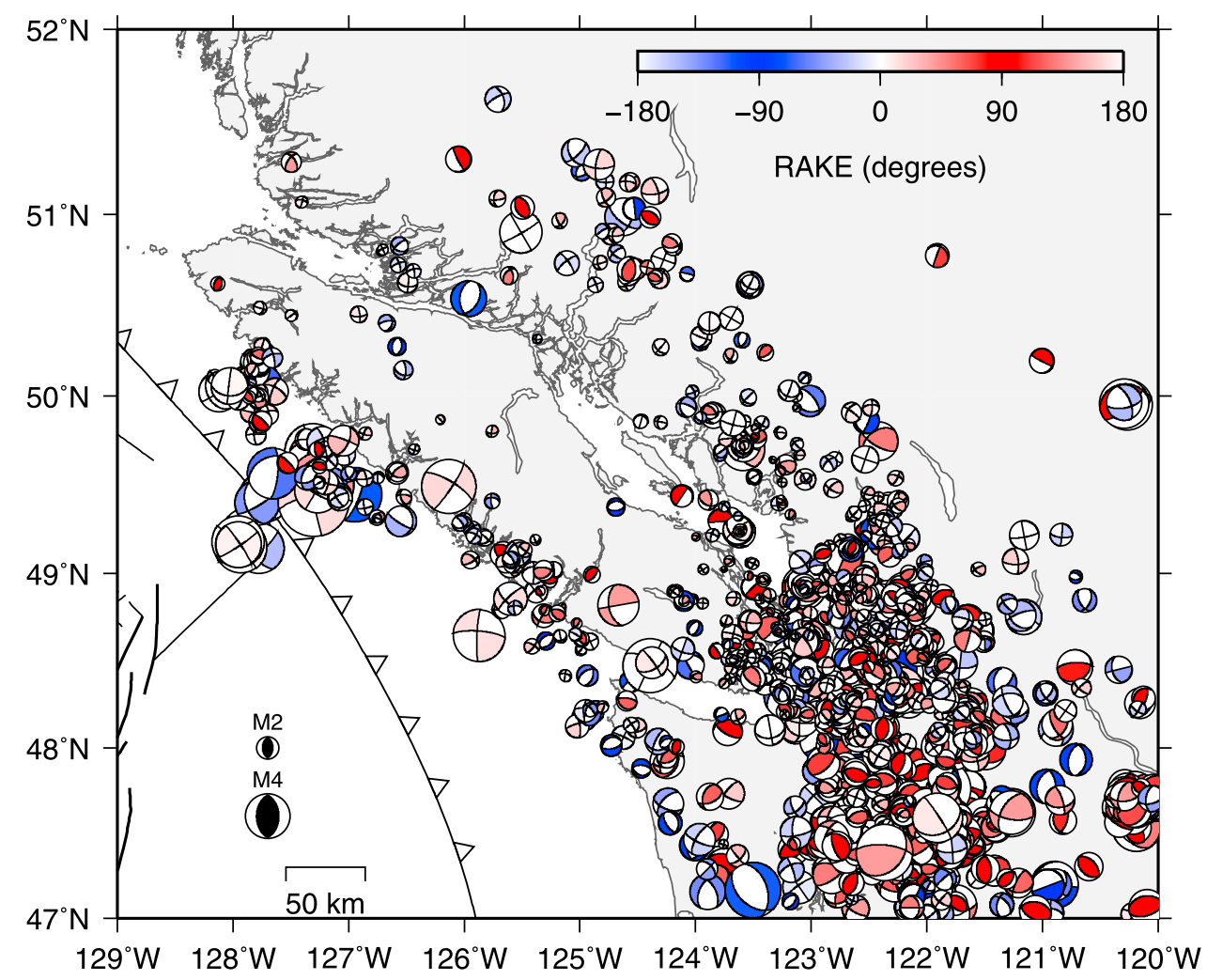

Figure 5. Updated focal mechanisms database for earthquakes in the North American crust colored according to rake: red indicates pure thrust faulting, blue is pure normal faulting, and white is strike-slip faulting.

distance to define the pick uncertainty as the signal-to-noise information is not always available. The other weighting function is related to how close an observation is to a nodal plane. If the source model is correct, the $\mathrm{P}$ wave radiation is minimum at the nodal planes and it is therefore difficult to correctly pick first motion here. Hence, observations near modeled nodal planes are down weighted. The inversion also attempts to formally estimate the uncertainty in the solution. These uncertainties are taken into consideration for the final grading of the focal mechanism where a quality grade from $1-5$ is given to be consistent with focal mechanisms determined in previous studies. The grading of the solution is described in Mulder [1995] where 1 is excellent and 5 is very poor. When grading solutions, several factors are considered: solution uncertainty from the inversion, alternative solutions, and mispicked first motions.

[12] In this study, before stress inversions were performed, an updated focal mechanism database is required. As discussed previously, the database was complete from 1975-1991 for all events with $M>1$ and from 1975-2007 for events with $\mathrm{M}>4$. To complete the database, focal mechanisms determined between 1992-2001 were reviewed and assigned quality grades. We attempted to determine focal mechanisms for all $M>1$ crustal events from 2002-2009 that have more than six first motion measurements.

[13] A total of 550 new focal mechanisms for crustal earthquakes in southwest British Columbia were calculated (Figure 3), increasing the database to 939 events. Ternary diagrams show focal mechanism information $(\mathrm{P}, \mathrm{T}$ and $\mathrm{B}$ axes) in Figure 4 [Frohlich, 1992] and determine the dominant style of faulting based on definitions developed for the World Stress Map Project by Zoback [1992]. There is a great deal of variability in the faulting styles, but significantly fewer normal faulting events: only $10 \%-14 \%$ of the focal mechanisms are considered normal faulting, while strike-slip faulting and thrust faulting occur $30 \%$ and $27 \%$ $33 \%$ of the time, respectively, and $23 \%$ are considered undefined (Figure 4).

[14] Faulting style is important for probabilistic hazard analysis as it can help by (1) defining seismic source zones using small earthquakes and (2) determining the appropriate attenuation relationship in a given region for moderate to large events $(\mathrm{M}>4)$ [Convertito and Herrero, 2004; Bozorgnia et al., 2010]. In general, the focal mechanisms in Figure 5 show highly variable faulting styles between closely spaced events, making it difficult to choose a style of faulting for a hazard model. However, there are some exceptions. The Coast Mountains region north of Vancouver experiences

Table 1. Conversion Between Quality Grades for Focal Mechanisms Defined by Mulder [1995] and Uncertainties in the Strike, Dip, and Rake for Input Into the Bayesian Stress Inversion

\begin{tabular}{cc}
\hline Quality Grade & Uncertainty $\left(^{\circ}\right)$ \\
\hline 1 & 5 \\
2 & 10 \\
3 & 20 \\
4 & 30 \\
5 & not used \\
\hline
\end{tabular}


a)

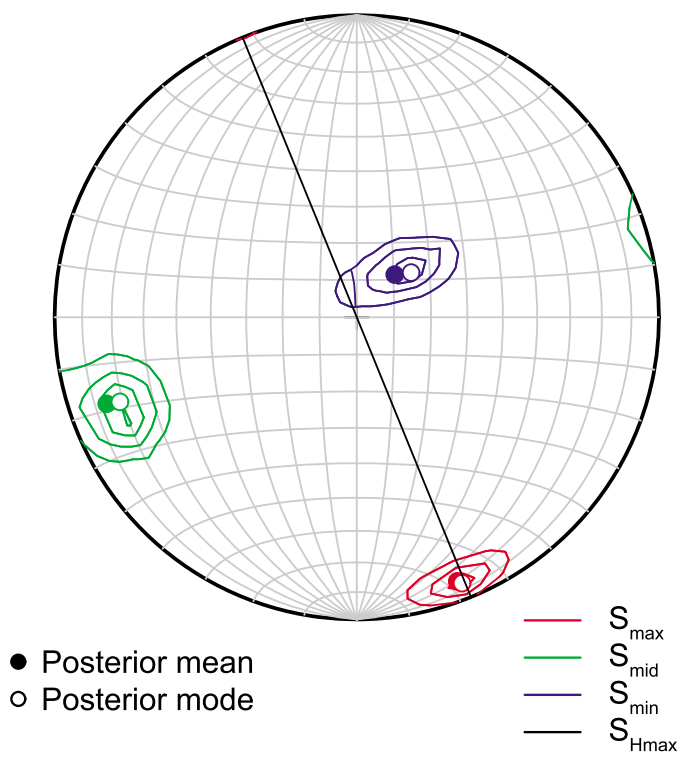

b)

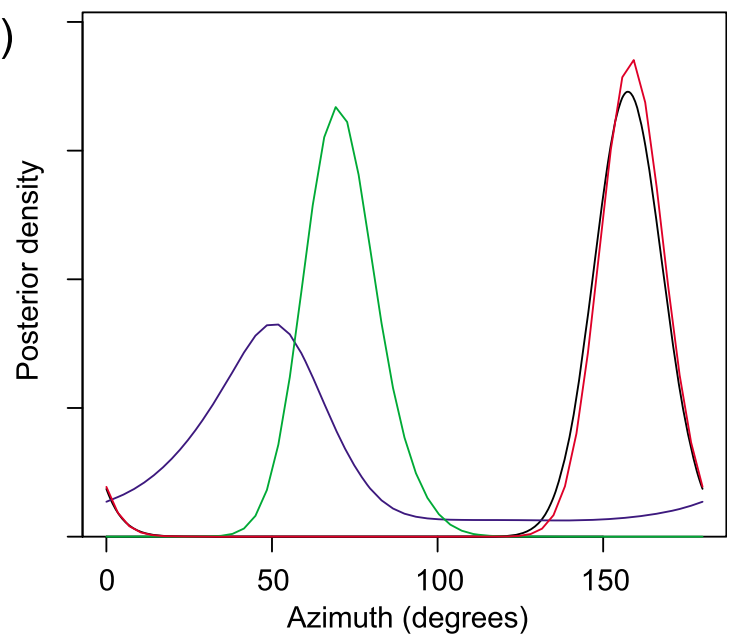

c)

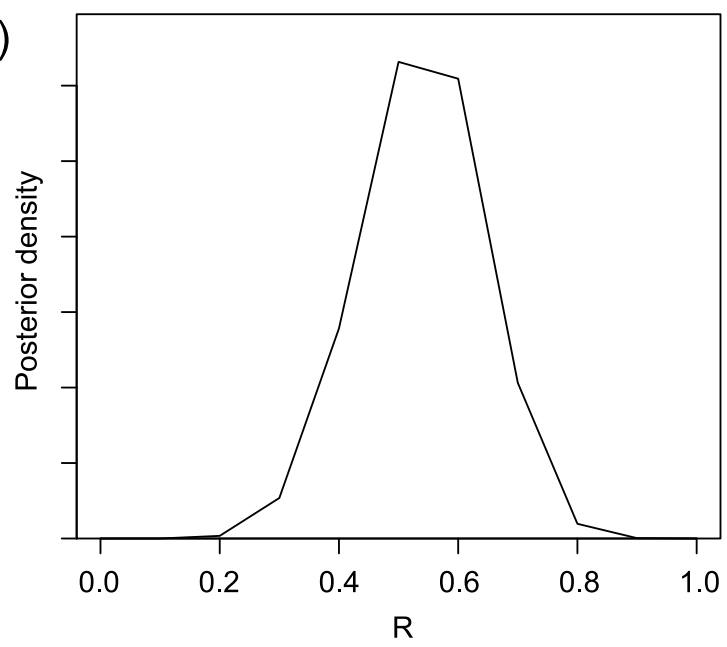

Figure 6. Example output of Bayesian stress inversion for group 1 in Figure 7. (a) PPD contours for the three principle stresses and $S_{\text {Hmax }}$ in a stereographic projection. The open and closed circles represent the posterior mode and mean, respectively. (b) Marginal PPDs for the stresses and $S_{\text {Hmax }}$ as a function of azimuth. (c) Marginal PPD of the stress ratio. dominantly strike-slip faulting with no pure-normal or purethrust faulting events, and southern Puget Sound experiences dominantly thrust faulting with few normal faulting events.

[15] The variation in faulting indicates a complex style of deformation, possibly including old reactivated faults and conjugate faults. It appears that faulting is more likely to occur on numerous smaller faults over a large area rather than a more narrow "San Andreas" type fault system. The dominant mix of strike-slip and thrust faulting suggests that the intermediate and least compressive stresses may be of similar magnitude, which is in agreement with previous studies [Wang and Jiangheng, 1999; Wang, 2000].

\section{Stress Inversion}

[16] To determine the in situ stress, we invert focal mechanisms for the four stress parameters: the orientations of the three principal stress axes (maximum $S_{1}$, intermediate $S_{2}$ and minimum $S_{3}$ compressive stress) and the stress ratio $(R)$.

[17] McKenzie [1969] demonstrated that a single focal mechanism puts little constraint on the stress tensor, as all that can be determined is that the axis of maximum compressive stress lies somewhere in the dilatational quadrant. Wallace [1951] and Bott [1959] hypothesized that slip on a fault occurs in the direction of maximum shear stress, which depends on both the orientation of the fault plane in the stress field and the relative magnitude of the principal stresses. From this and the additional assumption that all motion on faults in a discrete volume of crust are caused by the same stress tensor, it is possible to invert a group of fault slip data or fault plane solutions for the principal stress directions and stress ratio. Lund [2000] explains that it is necessary to have at least four focal mechanisms to determine stress, however in this study we have found that more than 10 are required to provide a stable result.

[18] As focal mechanism data only deal with the direction of slip at the fault plane, the inversion does not constrain the magnitude of the principal stresses but yields the stress ratio, $R$, which describes the shape of the stress ellipsoid,

$$
R=\left(S_{2}-S_{3}\right) /\left(S_{1}-S_{3}\right)
$$

[19] There have been many approaches to the stress inversion problem, including deterministic linear approaches [Michael, 1984, 1987], grid searches [Gephart and Forsyth, 1984; Gephart, 1990; Abers and Gephart, 2001], and a probabilistic Bayesian approach [Arnold and Townend, 2007]. This study is based on the Bayesian approach.

\subsection{Bayesian Method}

[20] The benefits of using the Bayesian approach by Arnold and Townend [2007] is that prior knowledge of the stress tensor can be incorporated into the inversion and observational errors in the focal mechanism data may also be included. Each focal mechanism is described by a strike, dip, rake and precision $(\tau)$. The precision is a measure of the average uncertainty in the strike, dip and rake of the focal mechanism, e.g., if the error in the mechanism is low $\left(<10^{\circ}\right)$ the precision is high $(\tau=20)$, and is based on the MatrixFisher distribution. Similar to Arnold and Townend [2007], we do not include a previously determined estimate of the 


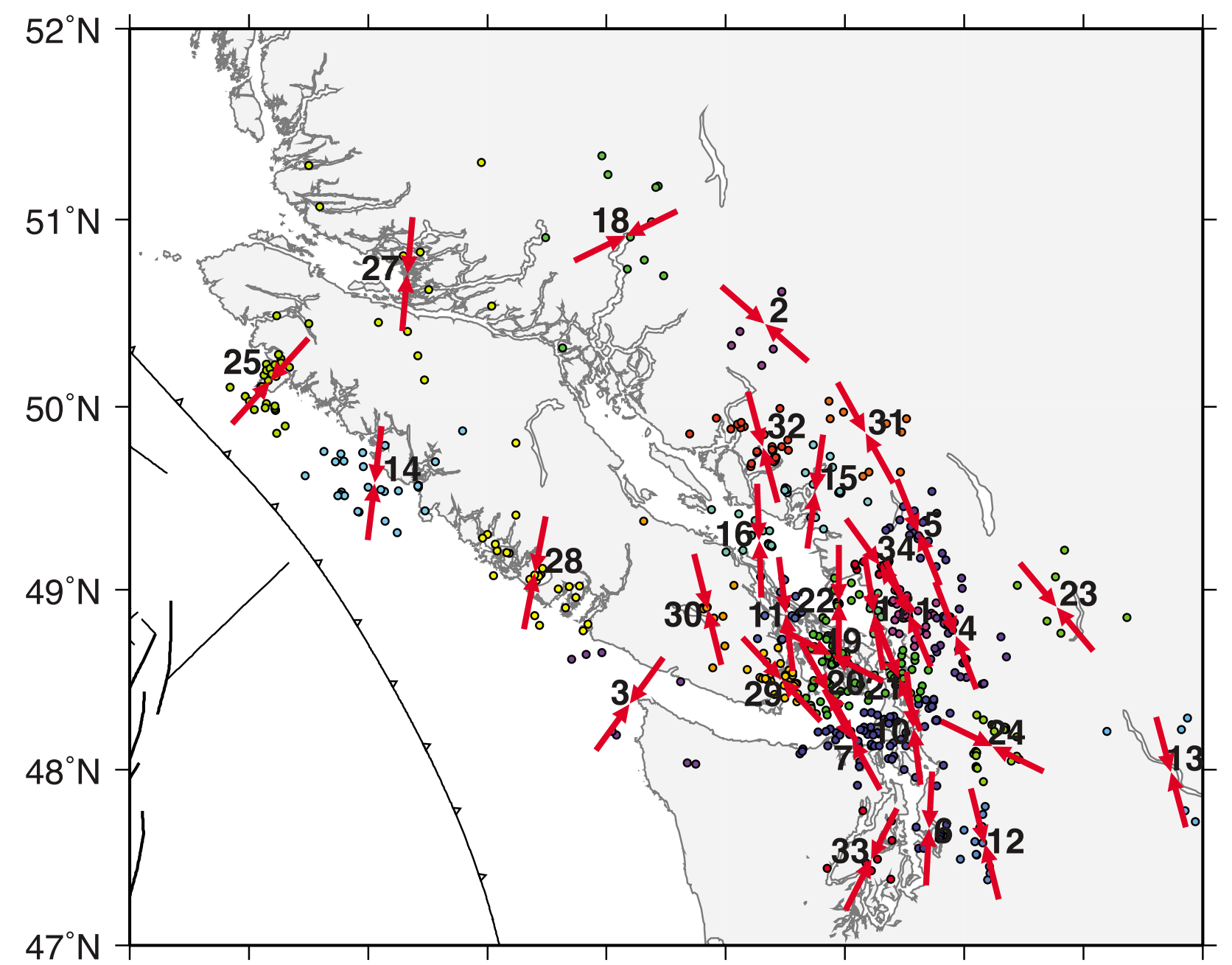

\section{$129^{\circ} \mathrm{W} 128^{\circ} \mathrm{W} 127^{\circ} \mathrm{W} 126^{\circ} \mathrm{W} 125^{\circ} \mathrm{W} 124^{\circ} \mathrm{W} 123^{\circ} \mathrm{W} 122^{\circ} \mathrm{W} 121^{\circ} \mathrm{W} 120^{\circ} \mathrm{W}$}

Figure 7. Stress inversion results. Maximum horizontal compressive stress is shown by the red arrows plotted at the center of each group. Locations of earthquakes are colored according to their cluster.

stress tensor orientation in the prior but assume its orientation is uniformly distributed. This can be done due to the reflectional symmetry of the stress tensor, which restricts the ranges of the Euler angles that transform the focal mechanism orientation to the orientation of the principal stress axes.

[21] As previously discussed, the focal mechanisms in the database are from multiple sources and not all sources include a complete description of the focal mechanism uncertainties. To address this, a quality grade was assigned to each mechanism which was then converted into an uncertainty based on Table 1 .

[22] To observe spatial variations, the data were divided into subsets based on location. We chose to use a K-means clustering algorithm [MacQueen, 1967] to divide the data based on latitude and longitude, with an average of 20 focal mechanisms per cluster. The clustering does not include depth because few focal mechanisms are located in the uppermost $5 \mathrm{~km}$ of the crust, where stress is likely to change the most, so we assume stress remains constant throughout the thickness of the crust. The clustering algorithm deter-

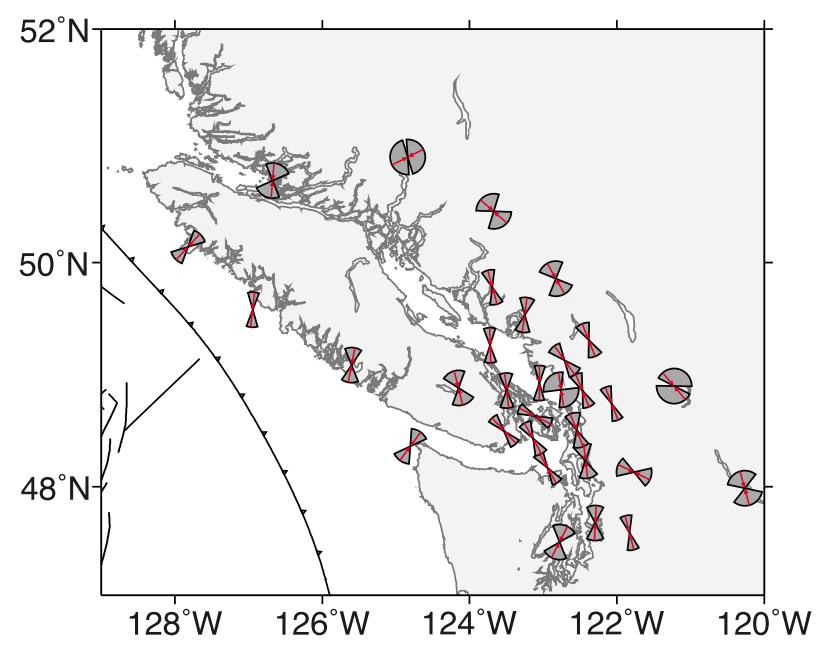

Figure 8. Maximum horizontal compressive stress directions plotted with wedges that show the $95 \%$ confidence of the result. 


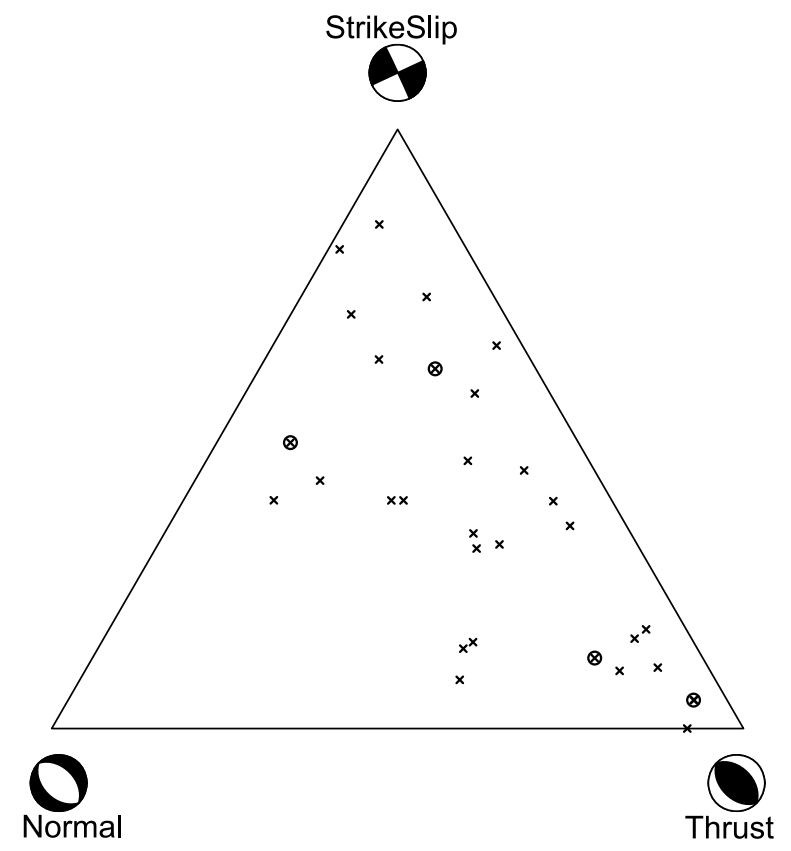

Figure 9. Ternary plot of stress results. Each point is plotted based on the plunge of the $S_{1}, S_{2}$, and $S_{3}$ axes of the mechanism. The crosses with circles are those groups along the west coast of Vancouver Island, and the crosses are the groups further inland. Note that these results fit within the distribution of the other groups even though their $S_{\operatorname{Hmax}}$ orientations differ.

mined 34 clusters, however three of these had too few events $(<4)$ for a stable inversion.

\subsection{Stress Results}

[23] Thirty-one groups of focal mechanisms were inverted for stress. The Bayesian inversion algorithm samples the posterior probability density (PPD) and computes marginal distributions, and the mode, mean and maximum a posteriori (MAP) estimation for each of the seven model variables (trend and plunge of the three principal stress axes and the stress ratio). An example of the output is shown in Figure 6. The inversion also calculates the maximum horizontal compressive stress direction $\left(S_{\text {Hmax }}\right)$ formulated by Lund and Townsend [2007], after Lund [2000]. $S_{\text {Hmax }}$ is plotted for each group on a map of the region in Figure 7 (red arrows). The $95 \%$ confidence region of $S_{H \max }$ for each group is shown in Figure 8. Groups 18, 23 and 27 have large asymmetric confidence regions because the majority of the focal mechanisms in these groups have low grades (3-4) and fewer focal mechanisms were used in the inversion (7-12).

[24] The results in Figure 7 show two distinct sets of stress orientations. One set is composed of results with northeastsouthwest orientation located on the west coast of Vancouver Island. The other set is composed of results located further inland, with stresses rotating from northsouth in Washington to northwest-southeast further north. The $S_{1}, S_{2}$ and $S_{3}$ axes from the stress inversions for each group are plotted on a ternary diagram in Figure 9 . The results range from strike-slip to thrust faulting regimes regardless of the $S_{\text {Hmax }}$ direction. Although there are normal faulting focal mechanisms in the database, the stress results are not consistent with a normal faulting regime.

\section{Comparison With GPS Strain Rates}

[25] To help identify the reason for the change in stress direction with distance from the margin, the $S_{\text {Hmax }}$ results are compared with the direction of maximum horizontal shortening $\left(e_{\text {Hmax }}\right)$ from Global Positioning System (GPS) strain data. A compilation of GPS data in southwest British Columbia and northwest Washington is used to derive crustal strain rate directions. As a first step, we derive horizontal GPS velocities using an updated version of the analysis described by Mazzotti et al. [2003]. The horizontal GPS velocities include results from about 40 permanent stations from 1996-2008 (including western Canada Deformation Array, Pacific Northwest Geodetic Array and Plate Boundary Observatory stations) and 60 campaign stations from 1992-1999, concentrated around Vancouver Island. The velocities from campaign data have a reduced weight in the calculations due to the lower quality of some data. The velocities, shown in Figure 10, are aligned to the International Terrestrial Reference Frame ITRF2000 and rotated relative to stable North America [Altamimi et al., 2002].

[26] To a first order, the horizontal GPS velocities mainly reflect the strain loading of the Cascadia forearc by the locked Cascadia subduction fault [e.g., McCaffrey et al., 2000; Mazzotti et al., 2003; McCaffrey et al., 2007]. This deformation is mostly elastic and will be recovered during the next Cascadia megathrust earthquake. The GPS velocities also contain smaller, secondary signals such as the margin-parallel shortening of the forearc that drives deformation and seismicity in the Puget Sound region [e.g., Mazzotti et al., 2002]. To separate these two components (subduction loading and forearc tectonics), we define two sets of GPS velocities: an original (uncorrected) set and a residual set corrected for the elastic interseismic loading from Cascadia subduction. The residual set is derived by removing model-based predicted velocities from the original GPS velocities. The predicted velocities are based on a 3-D elastic model of interseismic locking of the Cascadia subduction fault [Wang et al., 2003].

[27] To calculate the direction of strain rates from horizontal GPS velocities, we used an updated version of the velocity and strain rate smoothing method described by Mazzotti et al. [2001] consists of running a smoothing window on a grid to calculate interpolated horizontal velocity and strain rate tensor at each grid point from the GPS velocities. At each grid point, a Gaussian weighting function with an adaptive half-width and its spatial derivative were used to calculate the interpolated velocity and strain rate. The Gaussian half-width is defined based on the density of nearby GPS sites and a prescribed minimum wavelength (here $75 \mathrm{~km}$ ). The half-width varies between 75-100 km for the Vancouver Island-Puget Sound region, and increased to $100-200 \mathrm{~km}$ for the central and eastern British Columbia and Washington.

[28] At each grid point, the direction of maximum horizontal shortening rate was defined by the direction of the smallest of the two strain rate principal axes (extension 


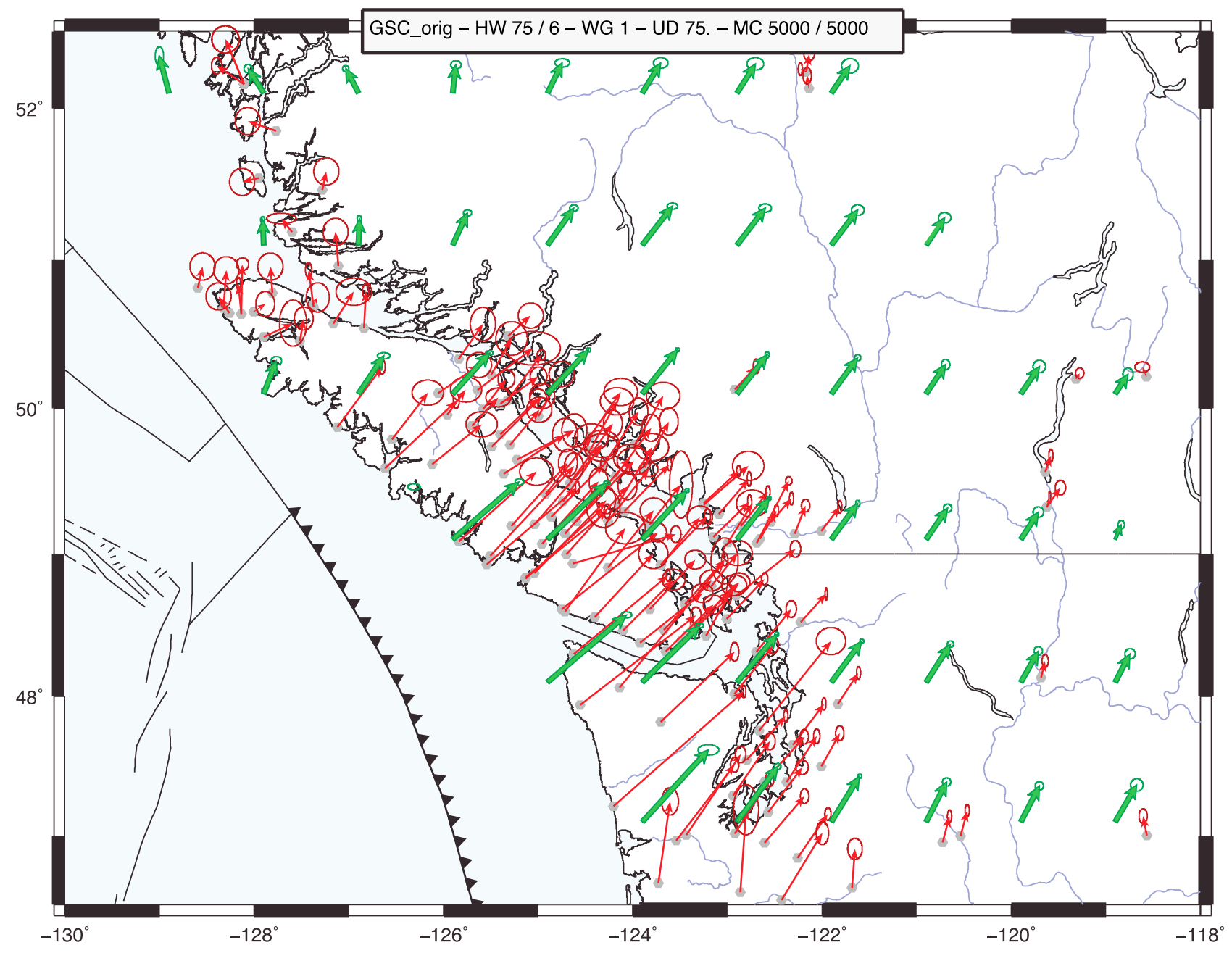

Figure 10. Observed GPS velocity field (red arrows with error ellipses) and smoothed velocities (green arrows with error ellipses) used to derive strain rates in Figure 11a.

positive convention). In the very few cases where the strain rate tensors are pure extension, this direction actually represents that of minimum horizontal extension. The standard errors on the strain rate tensor components, including the principal axis directions, are based on a numerical simulation that accounts for (1) the standard error on the input GPS velocities; (2) the coherence of the GPS velocities used to derive the strain rate tensor; and (3) the density of GPS sites near the grid point.

[29] We compared $e_{\text {Hmax }}$ to the $S_{H \max }$ directions from focal mechanism inversion in Figure 11, as they are expected to be similar based on Hooke's law. The results of the two GPS strain calculations (original and residual) and their standard errors are shown in Figure 11. $S_{\text {Hmax }}$ and $e_{\text {Hmax }}$ values used for the comparison as well as the velocity field used for the calculations can be found in the auxiliary material (Table S1 and Figures S1 and S2). ${ }^{1}$ The uncertainties illustrate the poorly resolved results in residual strain rates where the orientation changes from northwest to northeast near the Coast Mountains. We investigated the

\footnotetext{
${ }^{1}$ Auxiliary materials are available in the HTML. doi:10.1029/ 2010JB008003.
}

effect of the amount of locking in the subduction model on the residual strain rate directions by considering a range of models with varied amounts of locking from $0-100 \%$. We show the results of residual strain rates from removing models with $75 \%$ and $100 \%$ locking in Figures $11 \mathrm{~b}$ and $11 \mathrm{c}$, respectively. Models with less than $75 \%$ locking are very similar to the observed GPS strain rates (Figure 11a) and are therefore not included. The main effect the locking model has on the residual strain rate directions is how far inland the $e_{\text {Hmax }}$ directions changes from margin perpendicular to margin parallel; that is, the higher the locking in the model, the further from the margin this change in direction occurs.

[30] The results in Figure 11 show similar $S_{H \max }$ and $e_{\text {Hmax }}$ orientations along the west coast of Vancouver Island when the subduction component is included (Figure 11a), however they differ further inland from the margin. The residual strain rates shows similar directions for $S_{H \max }$ and $e_{H \max }$ further from the coast near Victoria and Vancouver, and different directions along the coast (Figure 11c). This agrees with studies by Wang [2000] which suggest stress is strongly influenced by subduction loading near the coast where the overriding plate is coupled with the subducting plate, while further inland, where they are less strongly 
a) Observed
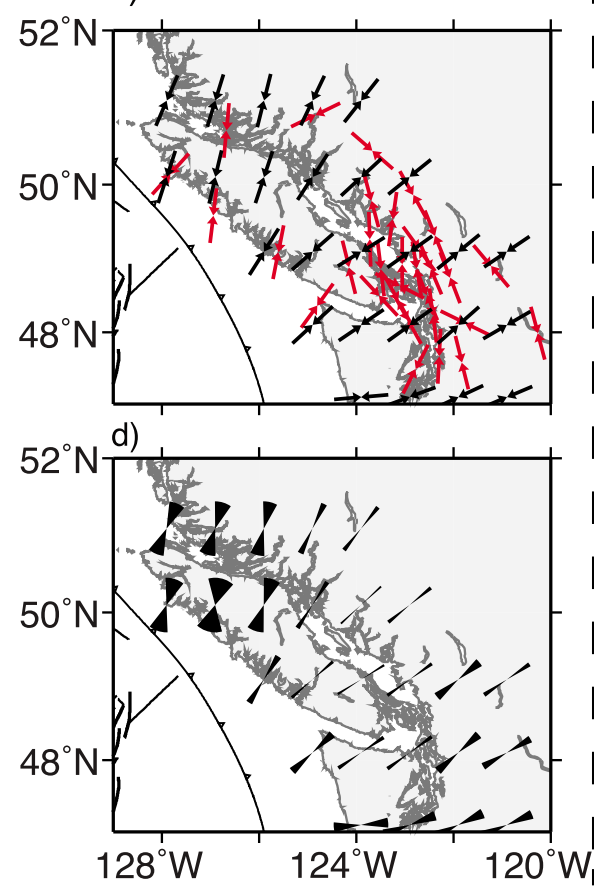

b) Residual: $75 \%$ Locked

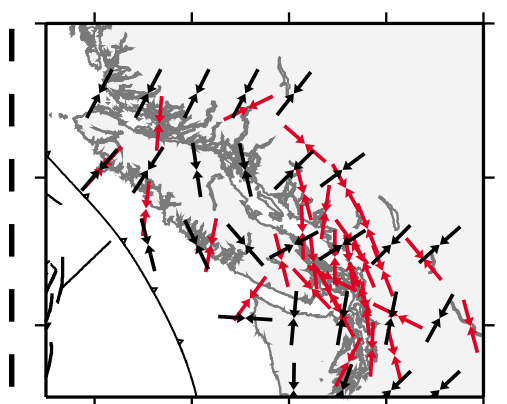

e)

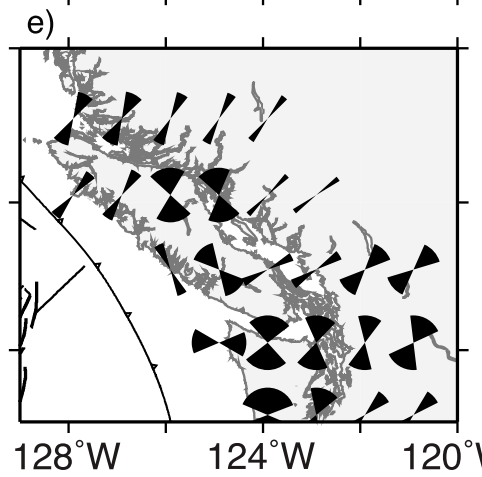

c) Residual: $100 \%$ Locked
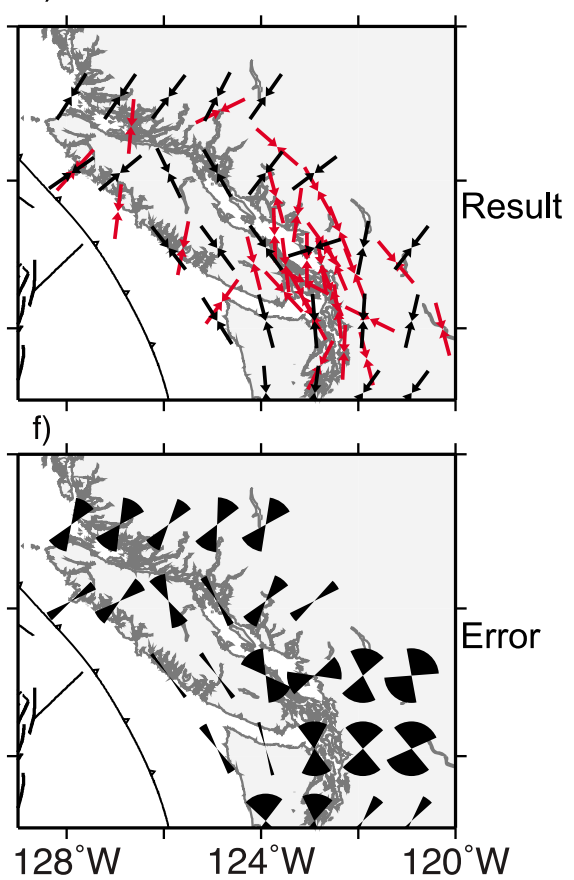

Figure 11. Comparison of $S_{H \max }$ (red arrows) with the $e_{H \max }$ direction from GPS strain rates (black arrows). GPS strain was calculated as the (a and d) observed and (b, c, e and f) residual, where the residual has the modeled subduction component removed. Two subduction models are shown with different amounts of locking on the subduction thrust; $75 \%$ (middle, Figures $11 \mathrm{~b}$ and $11 \mathrm{e}$ ) and $100 \%$ (right, Figures $11 \mathrm{c}$ and 11f). Figures $11 \mathrm{~d}-11 \mathrm{f}$ show wedges representing the standard error of the $e_{H \max }$ in each case.

coupled, stress is related to the residual strain due to the northward push of the Oregon Block. Wells and Simpson [2001] and McCaffrey et al. [2007] identified the Oregon Block from GPS velocities and describe it as rotating clockwise, with a northward motion along the coast of southern Washington and Oregon.

\section{Implications for Understanding Tectonics}

[31] The tectonics of southwest British Columbia are complicated by the locked Cascadia subduction zone, the bend in the subducting plate, the change in strike of the margin and the northward push of the Oregon Block. The stress results reflect the dominant strain accumulation which changes across the region. Near the margin, along the west coast of Vancouver Island, earthquakes in the upper plate are caused by the strain buildup due to the convergence of the North American and Juan de Fuca plates. This is due to the locked interface between the plates and the transfer of stress to the upper plate causing it to deform by shortening and uplift. The deformation was recognized and is well documented as part of the great earthquake cycle proposed by Atwater [1987], Rogers [1988] and Dragert et al. [1994]. Approximately $150 \mathrm{~km}$ inland, the stress results reflect the residual strain. The residual strain rate reflects the permanent crustal deformation caused by the northward push of the Oregon Block. The direction of this push rotates with the strike of the subduction zone to keep it approximately margin-parallel. Results from Ramachandran et al. [2006] show the presence of the mantle wedge sepa- rating the two plates approximately where the stress results change orientation. This implies that the change in orientation could be related to the lack of coupling between the plates. Figure 12 gives a cartoon representation of these two dominant forces. Studies investigating stress and strain at other subduction zones, such as the Nankai Trough, Japan Trench [Townend and Zoback, 2006] and the Peru-Chile Trench [Lavenu and Cembrano, 1999; Wang et al., 2007], also suggest

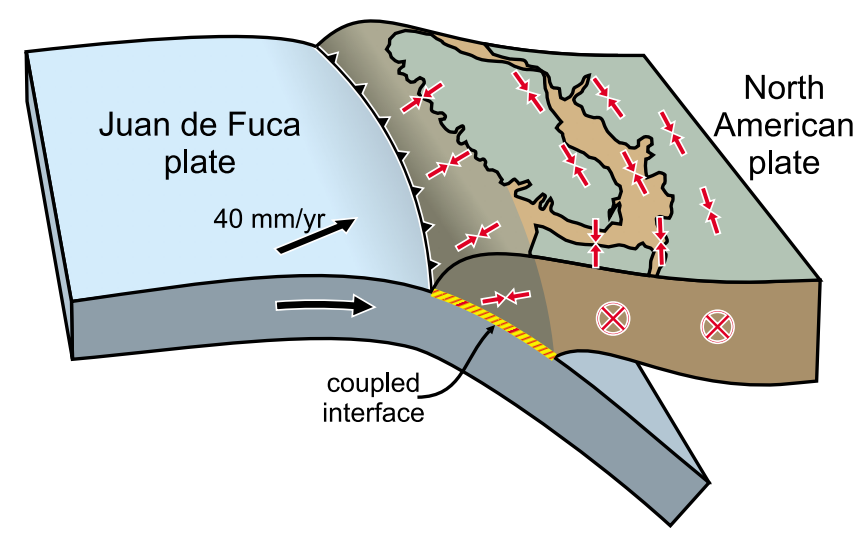

Figure 12. Cartoon representation of the dominant stress orientations (red arrows) in southwest British Columbia. The red crosses in circles represent motion into the page due to the northward push of the Oregon Block, which changes the stress orientation. 
that stress in the forearc reflects the residual deformation rather than that due to the subduction-earthquake cycle.

[32] The faulting regime across the whole region is varied and does not reflect a single dominant style. Instead, there is a range of faulting styles which predominately include oblique thrust and strike slip faults. The variety in faulting styles may be due to (1) the reactivation of old faults in an already highly fractured crust and (2) similar magnitudes for the intermediate and least compressive stress. British Columbia is made up of five large accreted terranes with a northwest-southwest orientation. These terranes have a long history of deformation before accretion and are complicated internally by a mix of volcanic and metamorphic compositions. Faulting preferentially occurs on optimally oriented structures according to Anderson's theory of faulting [Anderson, 1951] and the Mohr-Coulomb failure criterion [Byerlee, 1978]; however, existing structures that are not optimally oriented may also rupture if there are high pore fluid pressures and/or low friction strength. The variety of structures, including terrane boundaries, provide zones of weakness where these conditions may occur.

\section{Conclusions}

[33] The computation of $\sim 600$ focal mechanisms for crustal earthquakes in southwest British Columbia indicates a complex region of deformation with a range of faulting styles. Further analysis of the data shows that approximately equal amounts of $30 \%$ of faulting is strike-slip, thrust or some combination thereof, which only $10 \%$ of faulting is normal. Stress inversion results also show the stress regime favors strike-slip and thrust faulting.

[34] Stress inversions for groups of focal mechanisms across the region reveal a change in $S_{H \max }$ with distance from the subduction margin. Groups close to the margin show $S_{H \max }$ directions similar to $e_{\text {Hmax }}$ likely due to the coupled plate interface of the underlying subduction zone as determined from earlier studies. Further inland from the margin the stress is related to the residual strain from the northward push of the Oregon Block. This change in stress reflects the change from a coupled interface to weakly coupled plates separated by a mantle wedge.

[35] Acknowledgments. We would like to thank Richard Arnold and John Townend for their help accessing and using the Bayesian stress inversion code; Natasha Ruppert for the altered code for FPFIT with Antelope; the employees of Natural Resources Canada who maintain the CNSN catalogue and waveform archive; Richard Franklin for the cartoon representation of crustal stresses (Figure 12); and Kelin Wang and Garry Rogers who participated in helpful discussions. The facilities of the IRIS Data Management System, and specifically the IRIS Data Management Center, were used for access to some waveform and metadata required in this study. NSERC Discovery Grants provided funding for this project. Geological Survey of Canada contribution 20100277.

\section{References}

Abers, G., and J. Gephart (2001), Direct inversion of earthquake first motions for both the stress tensor and focal mechanisms and application to southern California, J. Geophys. Res., 106(B11), 26,523-26,540.

Altamimi, Z., P. Sillard, and C. Boucher (2002), ITRF2000: A new release of the international terrestrial reference frame for earth science applications, J. Geophys. Res., 107(B10), 2214, doi:10.1029/2001JB000561.

Anderson, E. (1951), The Dynamics of Faulting and Dyke Formation With Applications to Britain, Oliver and Boyd, Edinburgh.
Arnold, R., and J. Townend (2007), A Bayesian approach to estimating tectonic stress from seismological data, Geophys. J. Int., 170(3), 1336-1356, doi:10.1111/j.1365-246X.2007.03485.

Atwater, B. F. (1987), Evidence for great Holocene earthquakes along the outer coast of Washington State, Science, 236, 942-944, doi:10.1126/ science.236.4804.942.

Bolton, M. (2003), Juan de Fuca plate seismicity at the northern end of the Cascadia subduction zone, M.S. thesis, Univ. of Victoria, Victoria, B. C., Canada.

Bott, M. (1959), The mechanics of oblique slip faulting, Geol. Mag., 109-117.

Bozorgnia, Y., M. Hachem, and K. Campbell (2010), Ground motion prediction equation ("attenuation relationship") for inelastic response spectra, Earthquake Spectra, 26(1), 1-23.

Byerlee, J. (1978), Friction of rocks, Pure Appl. Geophys., 116, 615-626.

Cassidy, J., G. Rogers, and F. Waldhauser (2000), Characterization of active faulting beneath the Strait of Georgia, British Columbia, Bull. Seismol. Soc. Am., 90(5), 1188-1199.

Convertito, V., and A. Herrero (2004), Influence of focal mechanism in probabilistic seismic hazard analysis, Bull. Seismol. Soc. Am., 94(6), 2124-2136

Currie, C., J. Cassidy, and R. Hyndman (2001), A regional study of shear wave splitting above the Cascadia subduction zone: Margin-parallel crustal stress Geophys. Res. Lett., 28(4), 659-662.

DeMets, C., D. Gordon, D. Argus, and S. Stein (1990), Current plate motions, Geophys. J. Int., 101, 425-478.

DeMets, C., R. Gordon, D. Argus, and S. Stein (1994), Effect of recent revisions to the geomagnetic reversal time scale on estimates of current plate motions, Geophys. Res. Lett., 21(20), 2191-2194.

Dragert, H., R. Hyndman, G. Rogers, and K. Wang (1994), Current deformation and the width of the seismogenic zone of the northern Cascadia subducted thrust, J. Geophys. Res., 99, 635-668.

Frohlich, C. (1992), Triangle diagrams: Ternary graphs to display similarity and diversity of earthquake focal mechanisms, Phys. Earth Planet. Interiors, 75(1), 193-198.

Gephart, J. (1990), Stress and the direction of slip on fault planes, Tectonics, 9(4), 845-858.

Gephart, J., and D. Forsyth (1984), An improved method for determining the regional stress tensor using earthquake focal mechanism data: Application to the San Fernando earthquake sequence, J. Geophys. Res., 89(B11), 9305-9320.

Hyndman, R., G. Rogers, D. Dragert, K. Wang, J. Clague, J. Adams, and P. Bobrowsky (1996), Giant earthquakes beneath Canada's west coast, Geosci. Canada, 23(2), 63-72.

Lavenu, A., and J. Cembrano (1999), Compressional- and transpressionalstress pattern for Pliocene and Quaternary brittle deformation in fore arc and intra-arc zones (Andes of central and southern Chile, J. Struct. Geol., 21(12), 1669-1691.

Lewis, J., J. Unruh, and R. Twiss (2003), Seismogenic strain and motion of the Oregon coast block, Geology, 31(2), 183-186.

Lund, B. (2000), Crustal stress studies using microearthquakes and boreholes, Ph.D. thesis, Uppsala Univ., Uppsala, Sweden.

Lund, B., and J. Townend (2007), Calculating horizontal stress orientations with full or partial knowledge of the tectonic stress tensor, Geophys. J. Int., 170, 1328-1335, doi:10.1111/j.1365-246X.2007.03468.x.

MacQueen, J. (1967), Some methods for classification and analysis of multivariate observations, in Proceedings of the Fifth Berkeley Symposium on Mathematical Statistics and Probability, vol. 1, pp. 281-297, Univ. of Calif. Press, Berkeley.

Mazzotti, S., P. Henry, and X. L. Pichon (2001), Transient and permanent deformation of central Japan estimated by GPS: 2. Strain partitioning and arc-arc collision, Earth Planet. Sci. Lett., 184(2), 455-469.

Mazzotti, S., H. Dragert, R. Hyndman, M. Miller, and J. Henton (2002), GPS deformation in a region of high crustal seismicity: N. Cascadia forearc, Earth Planet. Sci. Lett., 198(1-2), 41-48.

Mazzotti, S., H. Dragert, J. Henton, M. Schmidt, R. Hyndman, T. James, Y. Lu, and M. Craymer (2003), Current tectonics of northern Cascadia from a decade of GPS measurements, J. Geophys. Res., 108(B12), 2554, doi:10.1029/2003JB002653.

McCaffrey, R., M. Long, C. Goldfinger, P. Zwick, J. Nabelek, C. Johnson, and C. Smith (2000), Rotation and plate locking at the southern Cascadia subduction zone, Geophys. Res. Lett., 27(19), 3117-3120.

McCaffrey, R., A. Qamar, R. King, R. Wells, G. Khazaradze, C. Williams, C. Stevens, J. Vollick, and P. Zwick (2007), Fault locking, block rotation and crustal deformation in the Pacific Northwest, Geophys. J. Int., 169(3), 1315-1340, doi:10.1111/j.1365246X.2007.03371.x.

McCrory, P., J. Blair, D. Oppenheimer, and S. Walter (2004), Depth to the Juan de Fuca slab beneath the Cascadia subduction margin: A 3-D model for sorting earthquakes, U.S. Geol. Survey Data Ser., DS-91. 
McKenzie, D. (1969), The relation between fault plane solutions for earthquakes and the directions of the principal stresses, Bull. Seismol. Soc. Am., 59(2), 591-601.

Michael, A. (1984), Determination of stress from slip data: Faults and folds, J. Geophys. Res., 89(B13), 11,517-11,526.

Michael, A. (1987), Use of focal mechanisms to determine stress: A control study, J. Geophys. Res., 92, 357-369.

Mulder, T. (1995), Small earthquakes in southwestern British Columbia (1975-1991), Ph.D. thesis, Univ. of Victoria, Victoria, B. C., Canada.

Ramachandran, K., R. D. Hyndman, and T. M. Brocher (2006), Regional $\mathrm{P}$-wave velocity structure of the northern Cascadia subduction zone, J. Geophys. Res., 111, B12301, doi:10.1029/2005JB004108.

Reasenberg, P., and D. Oppenheimer (1985), FPFIT, FPPLOT, and FPPAGE: Fortran computer programs for calculating and displaying fault-plane solutions, U.S. Geol. Survey Open File Rep. 85-0739.

Ristau, J., G. Rogers, and J. Cassidy (2007), Stress in western Canada from regional moment tensor analysis, Can. J. Earth Sci., 44(2), doi:10.1139/ E06-057.

Rogers, G. (1988), An assessment of the megathrust earthquake potential of the Cascadia subduction zone, Can. J. Earth Sci., 25(6), 844-852.

Rogers, G., and H. Hasegawa (1978), A second look at the British Columbia earthquake of June 23, 1946, Bull. Seismol. Soc. Am., 68(3), 653-675.

Townend, J., and M. Zoback (2006), Stress, strain and mountain building in central Japan, J. Geophys. Res., 111, B03411, doi:10.1029/ 2005JB003759.

Wada, I., S. Mazzotti, and K. Wang (2010), Intraslab stresses in the Cascadia subduction zone from inversion of earthquake focal mechanisms, Bull. Seismol. Soc. Am., 100(5A), doi:10.1785/0120090349.

Wallace, R. (1951), Geometry of shearing stress and relation to faulting, J. Geol., 59, 118-130.
Wang, K. (1996), Simplified analysis of horizontal stresses in a buttressed forearc silver at an oblique subduction zone, Geophys. Res. Lett., 23(16), 2021-2024

Wang, K. (2000), Stress-strain 'paradox', plate coupling, and forearc seismicity at the Cascadia and Nankai subduction zones, Tectonophysics, 319, 321-338.

Wang, K., and H. Jiangheng (1999), Mechanics of low-stress forearcs: Nankai and Cascadia, J. Geophys. Res., 104(B7), 15,191-15,205.

Wang, K., R. Wells, S. Mazzotti, R. Hyndman and T. Sagiya (2003), A revised dislocation model of interseismic deformation of the Cascadia subduction zone, J. Geophys. Res., 108(B1), 2026, doi:10.1029/ 2001JB001227.

Wang, K., Y. Hu, M. Bevis, E. Kendrick, R. Smalley Jr., R. Vargas and E. Lau (2007), Crustal motion in the zone of the 1960 Chile earthquake: Detangling earthquake-cycle deformation and forearc-sliver translation, Geochem. Geophys. Geosyst., 8, Q10010, doi:10.1029/2007GC001721.

Wells, R., and W. Simpson (2001), Northward migration of the Cascadia forearc in northwestern U.S. and implications for subduction deformation, Earth Planets Space, 53, 275-283.

Zoback, M. (1992), First-and second-order patterns of stress in the lithosphere: The world stress map project, J. Geophys. Res., 97(B8), $11,703-11,728$

N. J. Balfour and S. E. Dosso, School of Earth and Ocean Sciences, University of Victoria, Bob Wright Centre, Victoria, BC V8W 3V6, Canada. (nbalfour@uvic.ca)

J. F. Cassidy and S. Mazzotti, Pacific Geoscience Centre, Geological Survey of Canada, Sidney, BC V8L 4B2, Canada. 